\title{
A national survey on availability, price and affordability of selected essential medicines for non communicable diseases in Sri Lanka
}

Panthihage Ruvini L Dabare ${ }^{1}$, Chandanie A Wanigatunge ${ }^{2^{*}}$ and BVS Hemantha Beneragama ${ }^{3}$

\begin{abstract}
Background: Access to medicines is a universal right. Low availability and low affordability of medicines are issues that deny this right to a significant proportion of the world population. The objective of this study was to determine the availability, price and affordability of essential medicines prescribed to treat non communicable diseases in Sri Lanka.

Methods: Methodology was based on the 2nd edition of the World Health Organization Health Action International Manual. A country survey was conducted and facilities representing both public and private pharmacies were selected. A total of 109 facilities was surveyed. At each facility data on the availability and prices of 50 essential medicines for non communicable diseases were collected. Percentage availability, median price of originator brand and lowest priced generic, median price ratio to the International Reference Price were calculated for surveyed medicines. Affordability was determined using the daily incomes of the lowest - paid unskilled government worker.
\end{abstract}

Results: Semi government community pharmacies had the highest ( $>80 \%)$ availability while outdoor pharmacies of public health care facilities, private pharmacies and outdoor pharmacies of private hospital showed a fairly high availability $(50-80 \%)$ of surveyed medicines.

Unit price of $76 \%$ of selected individual medicines was less than ten Sri Lankan rupees. Out of these $28 \%$ of medicines cost less than one Sri Lanka rupee. For 21 of the surveyed medicines the median price ratio to the international reference price was less than one. The prices of originator brands for 14 surveyed medicines were more than five times that of the lowest price generics.

Less than a single day's wages was adequate to purchase a month's supply of the lowest priced generic of more than $67 \%$ of surveyed medicines.

Conclusions: The availability of selected essential medicines was fairly high in both public and private sectors in Sri Lanka. Most medicines are affordable to the lowest income earners in the community. There were many generic brands and generics available for most of the medicines in private and semi government community pharmacies increasing both availability and affordability.

Keywords: Availability, Affordability, Price, Essential medicines, Non communicable diseases

\footnotetext{
* Correspondence: caw@sjp.ac.lk

${ }^{2}$ Department of Pharmacology, Faculty of Medical Sciences, University of Sri

Jayewardenepura, Nugegoda, Sri Lanka

Full list of author information is available at the end of the article
} 


\section{Background}

Medicines that satisfy the healthcare needs of the majority of the population are defined as Essential Medicines (EM) [1]. They save lives, reduce suffering and improve health only if they are of good quality, safe, available and affordable. Selection of EM is based on the disease prevalence, evidence on efficacy, safety and comparative cost effectiveness in a particular country [2]. In addition to these the Sri Lanka essential medicines list (SL-EML) was compiled after considering the stability in various conditions, the needs of special diagnostic or treatment facilities and pharmacokinetic properties of drugs [3].

Availability and affordability are preconditions for universal access. Access is defined as having medicines continuously available and affordable at public or private health facilities or drug outlets that are within one hour's walk from homes of the population [1]. Affordability is measured by the cost required to buy a medication course for the indicated time for a particular disease in terms of the daily wage of the lowest-paid unskilled government worker [1]. Access to health care is a fundamental right and is included in international agreements and governmental policies. This fundamental right can be fulfilled by access to EM for priority diseases and is considered as one of the UN's Millennium Development Goals (MDGs) [4].

Many factors affect access to medicines. Unaffordable medicine prices, poor availability, irrational use of medicines, unfair health financing mechanisms, unreliable medicines supply systems, the quality of medicines and poor adherence of patients are among the factors that affect access to medicines [2].

Each year, chronic diseases cause approximately 35 million deaths (60\% of all deaths) globally with more than 30 million deaths (52\% of all deaths) due to cardiovascular diseases [5]. A significant proportion of morbidity and mortality due to chronic diseases can be prevented if medicines are made accessible and affordable. When medicines are used appropriate to control cardiovascular diseases, a cumulative relative risk reduction of about $75 \%$ can be achieved [6].

Yet one third of the global population lacks reliable access to needed medicines. It is worst in the poorest countries in Africa and Asia, where 50\% of population lacks access to medicines [4]. In a study done in 36 low and middle income countries in 2001-2006, the mean availability of EMs for non communicable diseases (NCD) was $36 \%$ in the public sector and $55 \%$ in the private sector [7] and the median availability of EM for chronic diseases in six low- and middle-income countries was less than $7.5 \%$ [8]. The probability of patients receiving at least one medicine for secondary prevention of cardiovascular disease depends on the country's income. It was $19.8 \%$ in low-income countries, $30 \cdot 7 \%$ in low-income and middle-income countries, and 54.9\% for upper-middle-income countries [9].

Availability of EM depends on the country budget for health. Average per capita spending on pharmaceuticals in high-income countries is 100 times higher than that of lowincome countries [4]. The World Health Organization (WHO) estimates that $15 \%$ of the world's population consumes over $90 \%$ of the global production of pharmaceuticals [4]. Compared to less than $10 \%$ allocation for medicines by most high income countries, the developing countries allocate $25-70 \%$ of overall health care expenditure for medicines [4]. However more medicines can be acquired within existing budgets with efficient selection, procurement, and use of generic medicines [7].

The NCD burden is increasing in Sri Lanka [10-12]. Of the 11 South East Asian Region (SEAR) countries, Sri Lanka ranks third with NCD accounting for $66 \%$ of total deaths [12]. The proportion of deaths due to circulatory diseases in Sri Lanka have increased from 3\% to 24\% over the last 50 years while hospitalization data of selected diseases show a steady increase in major NCD cases [12]. Hospital data which is currently collected only from the state sector show an increasing trend in hospitalization for NCD such as diabetes, hypertensive disease and ischemic heart diseases and mortality reports indicate that leading causes of deaths in public hospitals are cerebrovascular disease, acute myocardial infarction and heart failure $[10,11]$. As the elderly population of Sri Lanka are increasing and NCD are seen more in elderly $[13,14]$ this adds a considerable strain to an already overburdened healthcare system.

The current population of Sri Lanka is recorded as 20.2 million [15]. Of this $18.3 \%$ lives in the Urban sector, $77.3 \%$ in the Rural sector and the balance $4.4 \%$ in the Estate sector. Health care services to the people of Sri Lanka are provided by both public and private sectors. There are around 1638 health institutions in public sector and around 186 in private sector [10]. The public sector provides health care for nearly 60 percent of the population and encompasses the entire range of preventive, curative and rehabilitative health care aspects. The public health care institutions are classified into four levels according to the facilities available at the hospital by the Ministry of Health in Sri Lanka where level 1 has the minimum facilities.

Of the total government expenditure, about $5 \%$ is allocated to the health sector [11] and the public health care facilities provide services free of charge to all. The private sector provides mainly curative care services [10]. Primary health care is provided at all public sector hospitals by out-patient departments (OPDs) and the regular management of NCD is by the medical and other specialised clinics where specialist medical officers are available. While no published data is available from the 
private sector, this too provides both primary healthcare and inpatient services.

The Medical Supplies Division (MSD) of the Ministry of Health estimates the annual country need of medicines for public sector and the State Pharmaceuticals Corporation (SPC) procures them by a tender system. The MSD distributes the procured medicines to the government hospitals. The SPC also procures medicines for their community pharmacies (Rajya Osu Sala outlets) and through them, to other private health care facilities such as pharmacies attached to private hospitals and those owned by individuals and other private companies. The exception is only for narcotics where the supply to both public and private sectors is through the MSD.

All state hospitals have outdoor pharmacies that provide medicines free of charge to those that seek treatment from the outpatient departments and clinics of these institutions. If medicines are unavailable the patients would have to purchase these from pharmacies in the private sector. As there is no established health insurance scheme this results in out of pocket expenses to the patient.

Previous studies on availability and affordability of medicines in Sri Lanka have been conducted in limited geographical areas $[8,16,17]$. Thus a national survey was needed to ascertain availability, price and affordability in all provinces of the island to provide a better understanding of the situation. This survey was therefore conducted to identify the island wide availability of selected EM needed for treatment of NCD in public health care facilities and availability, price and affordability of those medicines in the private sector. To the best of our knowledge this is the first such island wide survey in Sri Lanka.

\section{Methods}

A national survey covering all nine administrative provinces was conducted to examine the availability and affordability of selected EM for NCD. Methodology was based on World Health Organization and Health Action International Manual (WHO/HAI) 2nd edition [4]. It explains in detail the methodology to conduct a reliable survey to measure availability and affordability of medicines in a geographical area or country and allows for international comparison.

Survey setting was outdoor pharmacies of public health care facilities and private pharmacies situated throughout the country. Outdoor pharmacies of public health care facilities, community pharmacies of SPC (Rajya Osu Sala outlets), outdoor pharmacies of private hospitals and private community pharmacies were taken as survey sectors as each sector has a difference pricing structure and availability.

The administrative provinces of the country were chosen as survey areas. The province's major urban centre (main public hospital) was identified to anchor the sample. A complete list of all public health care facilities in the province that is within three hours' travel from the major urban centre was created. For each survey area five public health care facilities representing all levels were selected and this always included the main public hospital of the province. Private pharmacies that are nearest to the selected public health care facility were identified and one Rajya Osu Sala Outlet and a separate private hospital was selected randomly for each public health care facility. An additional list of hospitals and pharmacies were maintained as a backup list. The sample size was in accordance with that recommended by the WHO/HAI Manual.

The WHO/HAI manual recommends to survey up to 50 medicines taken from global, regional and supplementary lists. Supplementary list for this study was the National List of Essential Medicines for Sri Lanka [18]. The surveyed medicines list included 9 medicines from the global core list, 10 medicines from the regional core list, and the rest from the SL-EML (Additional file 1: List of medicines surveyed).

Eleven NCD were identified to select the medicines list. Prevalence of the diseases and those that are managed in general medical clinics were considered to identify the most commonly treated NCD. The diseases identified were cardiovascular diseases (hypertension, ischaemic heart disease and heart failure), diabetes, asthma and chronic obstructive pulmonary diseases (COPD), peptic ulcers, osteoporosis, diseases of the thyroid, epilepsy, Parkinsonism, psychiatric disorders, joint related disorders (osteoarthritis, rheumatoid arthritis) and glaucoma.

Of the medicines surveyed 30 were stock items for all levels of health care facilities. Eight and 6 medicines selected should have been available as stock items in all institutions above level 2 and level 3 respectively. Only one of the selected medicines was restricted to level 4 institutions as a stock item. Although cancers are categorized under NCD, medicines used for cancers were not surveyed as patients with cancers are managed in selected hospitals in the country.

\section{Data collection}

Information on availability and affordability was obtained with an interviewer administered data collection form which was the survey tool. It was developed using the medicine price data collection form of the WHO/ HAI manual. Two main aspects were considered for data collection: availability and prices of the medicines to be surveyed. Availability data was collected from all selected pharmacies. Prices were collected from all pharmacies except those in public health care facilities. The prices were not obtained from public health care facilities as medicines are provided free of charge to patients from these institutions. Prices of generic equivalent 
products with the lowest unit price available at the facility and price of the innovator product of particular medicine were collected.

A pilot study was done by the principle investigator to find out the feasibility and limitation of carrying out the survey. All data collectors were pharmacy undergraduates and they were trained comprehensively before commencing the survey by conducting a workshop. Two data collectors collected data from one survey area to increase accuracy. Data from a single survey area were collected within a day by the data collectors and accuracy of data was ensured by comparing data of the two collectors from the same area. Data was collected from January to March 2013.

The data entering file was developed using SPSS software by the researchers. Data were entered by two persons and crossed checked to ensure accuracy. Hard and soft copies of data were stored for future reference.

\section{Data analysis}

The IBM SPSS statistic software (Version 21) and Microsoft Excel 2007 were used for statistical analysis such as calculating mean and median.

Availability of 50 essential medicines prescribed for NCD was analyzed by determining the mean percentage availability in survey areas, survey sectors, at hospital levels and for individual medicines. The availability of originator brand was determined for the private sector.

To describe the availability, following ranges were used as reference [19].

1. $<30 \%$ Very low

2. $30-49 \%$ Low

3. $50-80 \%$ Fairly high

4. $>80 \%$ High

\section{Determination of prices}

To determine price of each medicine, the unit price was taken for most medicines eg. price of a tablet, capsule, etc. Some medicines were considered as a unit package since they need to be bought as such eg. insulin vial, salbutamol syrup bottle, alendronic acid blister pack. The prices were taken in Sri Lankan Rupees (SLR) at the time of data collection and converted to US dollars (USD). The Currency conversion factor was taken according to WHO/HAI methodology and was the day of starting data collection. Currency values were taken from the Central Bank of Sri Lanka (1 SLR $=0.0079$ USD).

Median price of each medicine in local currency (SLR) and US Dollars (USD), median price of lowest priced generic (LPG) in relation to international reference price (IRP) [20] (ie Median Price Ratio (MPR)), comparison of MPR of originator brand $(\mathrm{OB})$ and lowest price generics were determined for individual medicines.

$$
\begin{aligned}
& \text { MPR }=\frac{\text { Median price of lowest priced generic }}{\text { International reference price }} \\
& \text { MPR of OB and LPG }=\frac{\text { Median price of originator brand }}{\text { Median price of lowest priced generic }}
\end{aligned}
$$

\section{Affordability}

Affordability was calculated considering Defined Daily Dose (DDD) and cost for a month's supply of each medicine was determined using the salary of the lowest paid unskilled government worker [20,21]. Affordability was not calculated for drugs that do not have DDD.

\section{Ethical considerations}

Ethical approval was granted by the Ethics Review Committee of Faculty of Medical Sciences, University of Sri Jayewardenepura (ERC approval no. 678/12) and administrative approval was given by the Secretary, Ministry Health.

\section{Results and discussion \\ Results}

One hundred and nine survey samples were selected from the nine survey areas (administrative provinces). Five outdoor pharmacies of public health care facilities, 5 private pharmacies (closest to each public health care facility), 1 semi government community pharmacy (Rajya Osu Sala outlet) and 1 outdoor pharmacy of a private hospital (closest to each public health facility, where present) from each survey area were included in the sample. There were 45 outdoor pharmacies of public health care facilities, 46 private pharmacies, 10 Rajya Osu Sala outlets and 8 outdoor pharmacies of private hospitals in the final sample.

\section{Availability}

The availability of the selected medicine was considered regardless of innovator/generic/branded generic.

\section{Percentage availability in survey sectors}

Island wide mean availability of medicines was $70.19 \%$ $( \pm 0.2)$. The mean availability was $58 \%( \pm 0.32)$ in the public sector and $74.37 \%( \pm 0.13)$ in the private sector. The median availability was $54 \%$ in the public sector and $76.1 \%$ in the private sector. The mean percentage availability of all selected medicines was calculated for each survey sector. The mean availability in the outdoor pharmacies of public health care facilities, Rajya Osu Sala outlets, private pharmacies and outdoor pharmacies of private hospitals were $58 \%( \pm 0.32), 89 \%( \pm 0.16), 71 \%$ $( \pm 0.23)$ and $63 \%( \pm 0.23)$ respectively.

Overall, a fairly high availability (50-80\%) of the medicines for NCD was seen in the survey sample. Rajya Osu Sala outlets had the highest availability among 
survey sectors while outdoor pharmacies of public health care facilities had the lowest.

\section{Percentage availability in survey areas}

The mean availability was survey areas (administrative provinces) ranged between $50-80 \%$ in 8 and was more than $80 \%$ in one.

The availability of medicines in survey sectors among survey areas was further analyzed. Only one survey area showed less than $50 \%$ availability (45\%) in outdoor pharmacies of public health care facilities. There were two survey areas showing less than $50 \%$ availability in outdoor pharmacies of private hospital. Rajya Osu Sala and private pharmacies showed more than $50 \%$ availability in all survey areas.

\section{Mean percentage availability of medicines at hospital levels} There were 4,13, 14, and 14 of levels $1,2,3$ and 4 public health care facilities respectively in the sample. Although 45/50 surveyed medicines should have been available in level 4 public hospitals, availability was only $64.6 \%$. The mean percentage availability according to the levels of public health care facilities is given in Figure 1.

Of the stock medicines $(30 / 50)$ that should have been available in Level 1 institutions, the availability was only $36.4 \%$. The single medicine (alendronic acid) that was supplied only to level 4 institutions, showed an availability of $30.8 \%$.

\section{Mean percentage availability for individual medicines}

The individual mean availability of $18 \mathrm{EM}$ was $>80 \%$. Twenty EM had an availability in the range of $50 \%$ to $80 \%$. Mean availability of 11 medicines was between $30 \%$ and $49 \%$.

The availability of medicines was determined according to therapeutic groups for particular disease such as cardiovascular disorders, diabetes and asthma in survey samples. Availability of selected medicines according to the therapeutic groups is given in Figures 2,3 and Table 1.

There was $0 \%$ availability of syrup sodium valproate in public health care facilities. A very low availability $(0-30 \%)$ was seen with aspirin $100 \mathrm{mg}$, gliclazide $80 \mathrm{mg}$, ipratropium bromide $40 \mu \mathrm{g}$, levodopa-carbidopa $100+$ $25 \mathrm{mg}$, lithium carbonate $300 \mathrm{mg}$, ranitidine $150 \mathrm{mg}$, and timolol $25 \%$ ophthalmic solution in the public sector.

\section{Mean availability of originator brands}

The mean availability of originator brands was determined only for the private sector including Rajya Osu Sala outlets. It was not considered for outdoor pharmacies of public health care facilities as public sector gives priority to procure the lowest priced generics. Only 30 originators were available in private pharmacies. Total availability of originator brand was $25.9 \%$. Seven originators had a fairly high availability $(50-80 \%)$. Three originator brands had an availability between $50-30 \%$ while 20 showed less than $30 \%$ availability.

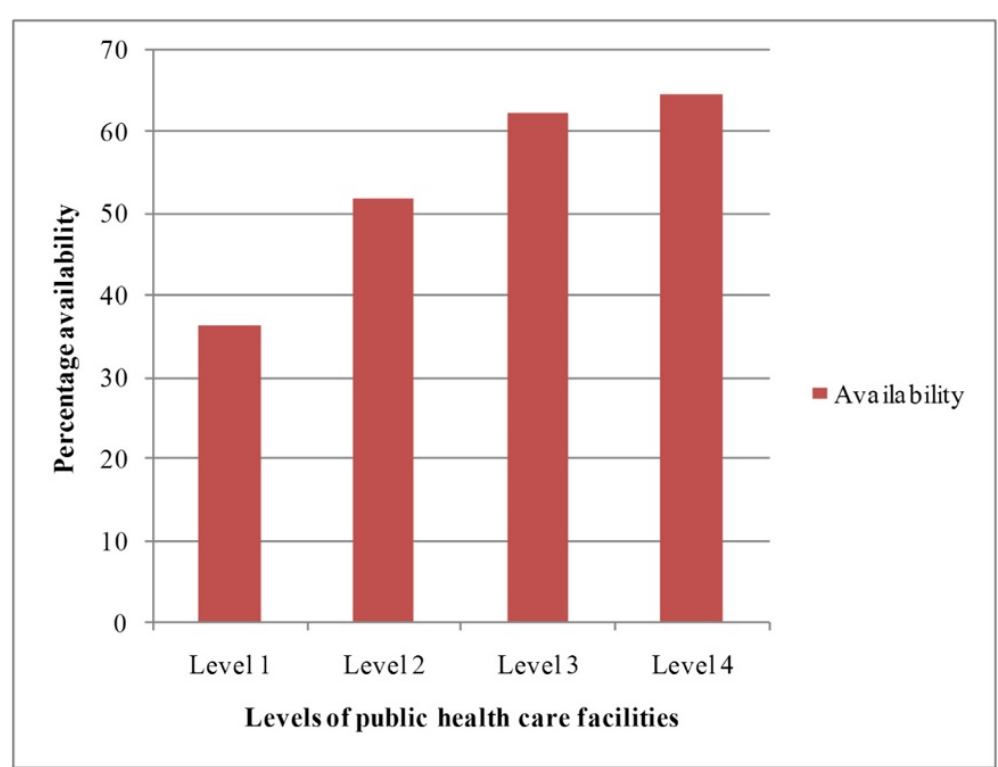

Figure 1 Availability of essential medicines according to the levels of public health care facilities. 


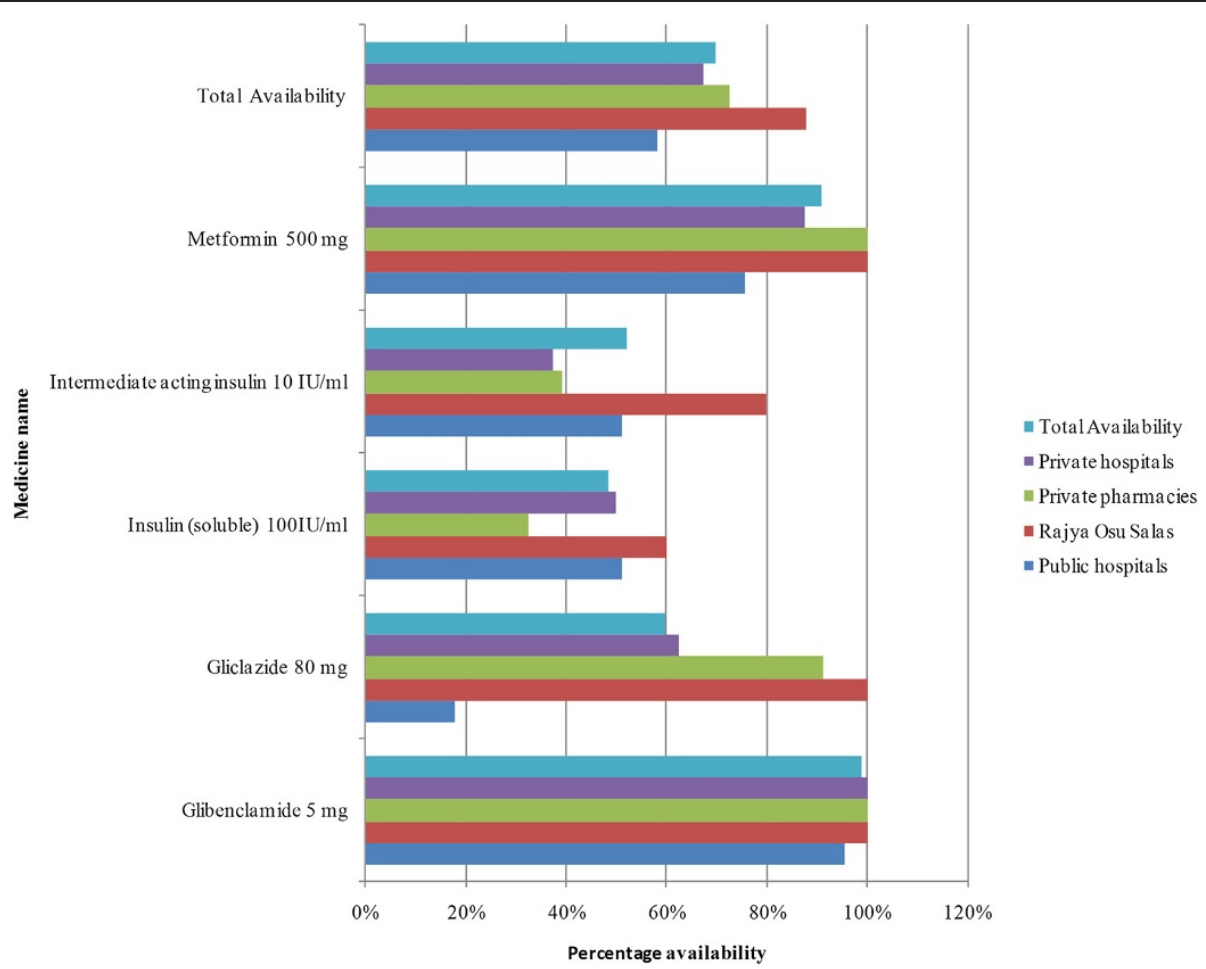

Figure 2 Availability of medicines for diabetes.

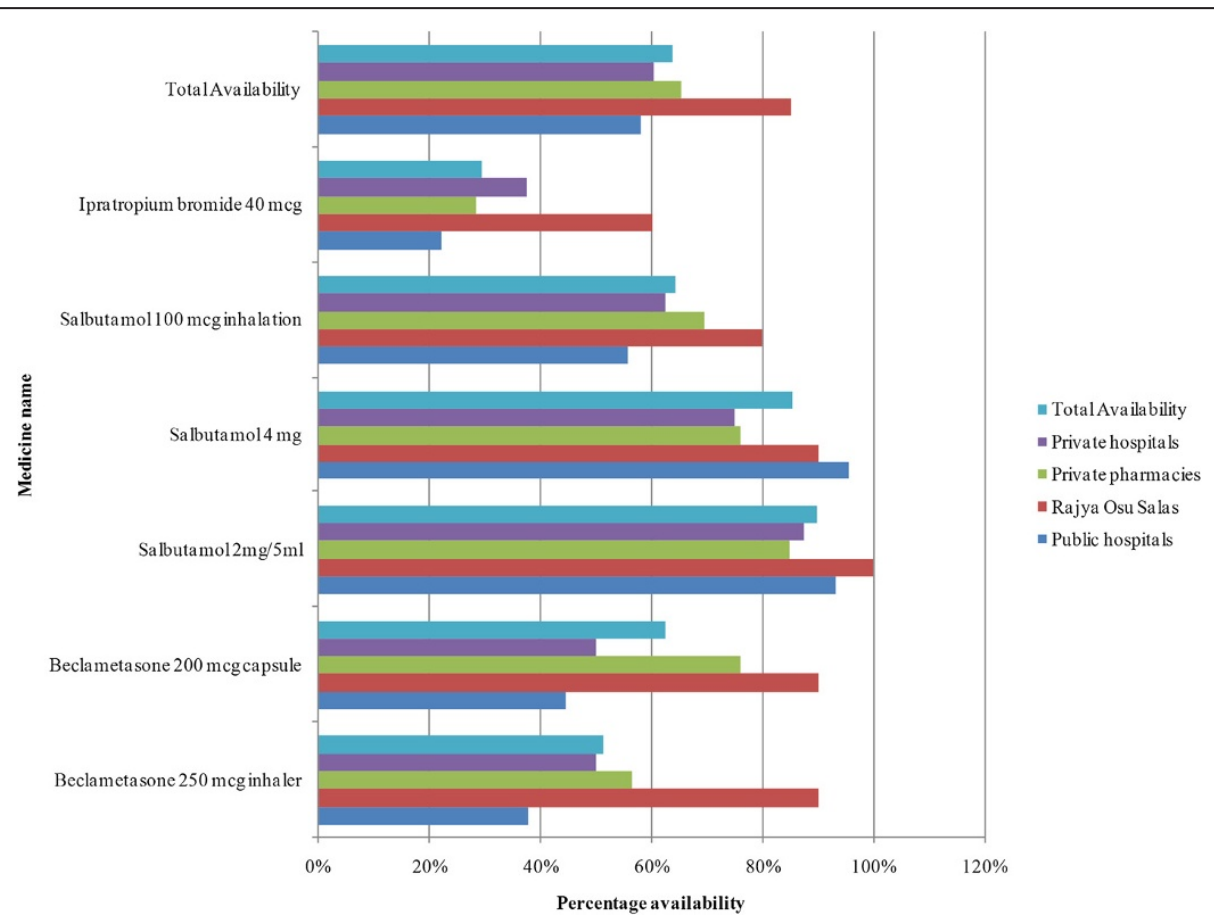

Figure 3 Availability of medicines for bronchial asthma. 
Table 1 Availability of cardiovascular drugs in survey sectors

\begin{tabular}{|c|c|c|c|c|c|}
\hline Drug name & $\begin{array}{l}\text { Public hospital } \\
\text { outdoor pharmacies }\end{array}$ & $\begin{array}{l}\text { RajyaOsu } \\
\text { Sala outlets }\end{array}$ & $\begin{array}{l}\text { Private } \\
\text { pharmacies }\end{array}$ & $\begin{array}{l}\text { Private hospital } \\
\text { outdoor pharmacies }\end{array}$ & $\begin{array}{l}\text { Average availability } \\
\text { in Sri Lanka }\end{array}$ \\
\hline Atenolol $50 \mathrm{mg}$ & $44 \%$ & $90 \%$ & $70 \%$ & $63 \%$ & $66 \%$ \\
\hline Glyceryltrinitrate $500 \mu \mathrm{g}$ & $93 \%$ & $90 \%$ & $30 \%$ & $50 \%$ & $66 \%$ \\
\hline Amlodipine $5 \mathrm{mg}$ & $37 \%$ & $100 \%$ & $89 \%$ & $50 \%$ & $70 \%$ \\
\hline Amiodarone $100 \mathrm{mg}$ & $50 \%$ & $80 \%$ & $33 \%$ & $38 \%$ & $46 \%$ \\
\hline Digoxin $62.5 \mu \mathrm{g}$ & $29 \%$ & $20 \%$ & $33 \%$ & $25 \%$ & $27 \%$ \\
\hline Verapamil 40 mg & $96 \%$ & $100 \%$ & $89 \%$ & $75 \%$ & $87 \%$ \\
\hline Enalapril 5 mg & $98 \%$ & $100 \%$ & $100 \%$ & $88 \%$ & $96 \%$ \\
\hline Captopril 25 mg & $100 \%$ & $100 \%$ & $89 \%$ & $75 \%$ & $89 \%$ \\
\hline Hydrochlorothiazide 25 mg & $98 \%$ & $50 \%$ & $67 \%$ & $75 \%$ & $73 \%$ \\
\hline Methyldopa 250 mg & $58 \%$ & $100 \%$ & $72 \%$ & $50 \%$ & $70 \%$ \\
\hline Nifedipine20 mg & $98 \%$ & $100 \%$ & $91 \%$ & $88 \%$ & $94 \%$ \\
\hline Carvedilol $6.25 \mathrm{mg}$ & $62 \%$ & $100 \%$ & $61 \%$ & $63 \%$ & $66 \%$ \\
\hline Furosemide 40 mg & $91 \%$ & $100 \%$ & $100 \%$ & $88 \%$ & $95 \%$ \\
\hline Spironolactone $100 \mathrm{mg}$ & $38 \%$ & $60 \%$ & $72 \%$ & $13 \%$ & $52 \%$ \\
\hline Atorvastatin $10 \mathrm{mg}$ & $91 \%$ & $100 \%$ & $87 \%$ & $88 \%$ & $91 \%$ \\
\hline Simvastatin $20 \mathrm{mg}$ & $2 \%$ & $100 \%$ & $54 \%$ & $38 \%$ & $49 \%$ \\
\hline Mean availability of cardiovascular drugs & $68 \%$ & $91 \%$ & $74 \%$ & $63 \%$ & $74 \%$ \\
\hline
\end{tabular}

\section{Medicine prices}

Median price of each medicine in local currency and US Dollars

There were 38 EMs less than 10 SLR and 5 medicines more than 500 SLR. Out of 50 medicines, 41 medicines prices were less than 1 USD and only two medicines were priced more than 10 USD.

The median prices of originator brands $(\mathrm{OB})$ were calculated and they were compared with lowest priced generic (LPG). The results are shown in Figure 4.
Median price in relation to the international reference price (Median Price Ratio (MPR))

MPR was calculated for 41 medicines with an IRP. The prices of 21 medicines were less than IRP of the particular generic medicine. The MPR was more than 5 for only one medicine.

\section{Comparison of MPR of originator brand and lowest price} generics

MPR of originator and lowest priced generic was taken. There were 14 medicines with ratio between $1-5$. The

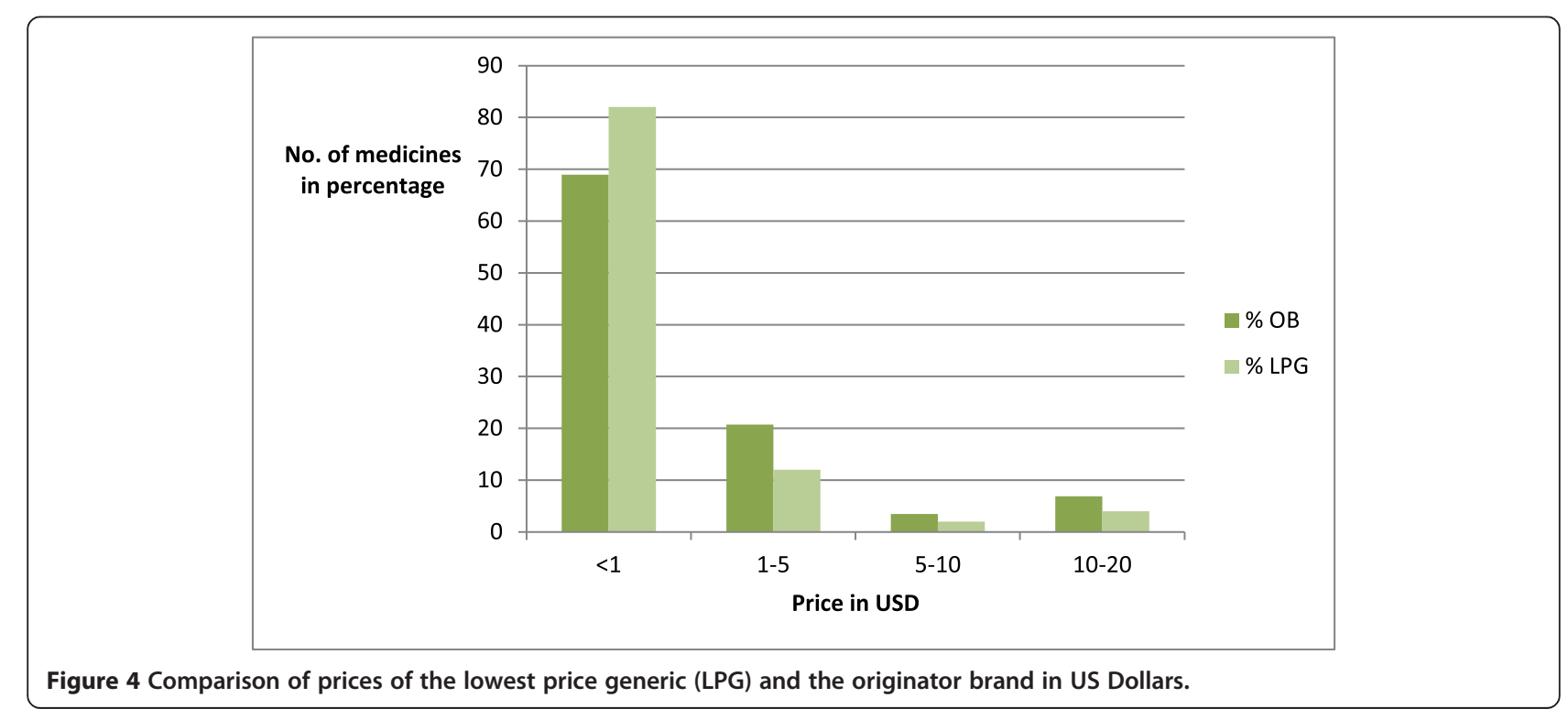


price of $10 \mathrm{OB}$ medicines was higher than $10-100$ times of LPG of particular medicines.

In most instances (96.6\%) the originator brand price was considerably higher than lowest priced generics.

\section{Affordability}

More than $67 \%$ of medicines required less than a single day's wages to purchase those medicines for a period of one month. Less than ten days' wages was required to buy a month's supply of 14 of the selected medicines (Table 2).

\section{Discussion}

Compared to studies done in other countries $[7,8]$ mean and median availability of surveyed essential medicines for NCD in both public and private sectors is fairly high in Sri Lanka. The public sector in Sri Lanka shows an improvement in median availability from $28 \%$ in 2006 [8] to $54 \%$ in 2013.The Rajya Osu Sala outlets which represent the government private sector community pharmacy chain system, had a high mean availability (89\%) of medicines in 2013.

Every level of public hospital had a fairly high availability of the EM surveyed. Although sodium valproate liquid preparation should be available in all levels of public health care facilities excluding level 1 , it had a $0 \%$ availability. This is similar to the findings of a previous study which showed $0 \%$ availability for carbamazepine syrup [17]. The unavailability of these medicines could be due to the absence of an EML for paediatric medicines. When compared with previous studies, availability of cardiovascular medicines in the public sector showed a significant improvement $[8,22]$.

The procurement and distribution system of MSD affects availability of medicines in the public sector. The low availability of some EM such as levothyroxine, levodopa-carbidopa, and lithium carbonate in public sector health care facilities is a concern that needs to be addressed.

Availability of surveyed originator brands was very low $(25.9 \%)$ and these were available only in very few private pharmacies. There were significant differences between the originator and generic availability. Generics had a high $(>80 \%)$ or a fairly high $(50-80 \%)$ availability in the private sector. Although two thirds of the registered originator brands were not available, there were many generics available for a particular medicine.

Although aspirin $300 \mathrm{mg}$ showed an overall availability of $78 \%$, the $100 \mathrm{mg}$ tablets had a low overall availability of $<50 \%$. This is a potential issue as low dose aspirin (75-150 $\mathrm{mg}$ ) is indicated for ischaemic heart disease. Salbutamol MDI which is widely prescribed as a reliever for acute asthma had an availability of only $55.6 \%$ in the public sector while salbutamol $4 \mathrm{mg}$ tablet and syrup $(2 \mathrm{mg} / 5 \mathrm{ml})$ were highly available $95.6 \%$ and $93.3 \%$ respectively. Although salbutamol tablets are not included in the 17th WHO Model List for Essential Medicines (EML) [23], Sri Lanka continues to retain this in national guidelines [24], EML and Hospital Formulary List (CAW: personal communication) as the inhaled forms are expensive. The high availability of atorvastatin when compared to simvastatin is likely due to the former being included in the SL-EML [18].

The lower median prices of some of the surveyed medicines when compared to their IRPs suggest that these medicines are cheaper than in the reference countries. This indicates that generic pricing in private pharmacies and Rajya Osu Sala outlets is appropriate. This finding is consistent with the prices reported previously [16].

A monthly prescription for 31 individual medicines was affordable to the lowest paid unskilled government

Table 2 The medicines that require more than one day's wage to buy the monthly requirement

\begin{tabular}{ll}
\hline Medicines & No. of daily wage required to buy monthly requirement \\
\hline Amiodarone $100 \mathrm{mg}$ tablet for cardiovascular diseases & 6.5217 \\
Beclometasone $200 \mu \mathrm{g}$ capsules for bronchial asthma & 2.4642 \\
Carvedilol $6.5 \mathrm{mg}$ tablet for cardiovascular diseases & 1.9666 \\
Glyceryl trinitrate $500 \mu \mathrm{g}$ tablet for angina & 2.0067 \\
Insulin (soluble) $100 \mathrm{IU} / \mathrm{ml}$ vial for diabetes & 6.5819 \\
Intermediate acting insulin $10 \mathrm{IU} / \mathrm{ml}$ vial for diabetes & 5.6187 \\
Ipratropium bromide $40 \mu \mathrm{g}$ capsule for bronchial asthma & 2.0167 \\
Levodopa- carbidopa $100+25 \mathrm{mg}$ tablet for parkinsonism & 13.6656 \\
Methyldopa $250 \mathrm{mg}$ tablet for cardiovascular diseases & 2.0789 \\
Phenytoin $100 \mathrm{mg}$ tablet/capsule for epilepsy & 1.1649 \\
Salbutamol $100 \mu \mathrm{g}$ inhalation (MDI) for bronchial asthma & 1.1880 \\
Simvastatin $20 \mathrm{mg}$ tablet/capsule for cardiovascular diseases & 1.2040 \\
Sodium valproate $200 \mathrm{mg}$ tablet for epilepsy & 4.7634 \\
Sodium valproate $200 \mathrm{mg} / 5 \mathrm{ml}$ syrup for epilepsy & 1.4403 \\
\hline
\end{tabular}


worker in Sri Lanka. Fourteen medicines required 1-10 daily wages to buy the monthly requirement of medicines using LPG. Therefore medicines are generally affordable to the lowest income community in the country and this finding is consistent with that of previous studies $[8,16]$.

The relatively low availability of medicines in outdoor pharmacies of public health care facilities is a concern as the MSD should supply the medicines surveyed to all institutions selected in the survey. The resultant out of pocket expense to the patient could lead to non compliance depending on the patient's financial status.

\section{Limitations}

This survey was conducted at the beginning of the year where most medicines are expected to be available in public health care facilities. Availability may change depending on the time of the year and hence these findings may not reflect the situation throughout the year.

Although affordability was calculated based on the daily wage of an unskilled government worker there may be people with an income less than this and thus the affordability data may not be a true reflection of affordability.

\section{Conclusions}

Over all availability of EM for NCD was fairly high in both public and private sectors at the time of surveying. The availability of many generic brands and generics in private pharmacies including the Rajya Osu Sala outlets provide patients with an opportunity to purchase medicines within their budget and the people need to be educated about this option.

The comparatively lower availability of EM in outdoor pharmacies of public health care facilities needs to be improved. Existing policies and procedures should be strengthened to forecast requirements and for timely procurement to ensure a steady and uninterrupted supply to the public health care facilities. This will improve both availability and affordability to a vast majority of the country's population which in turn will reduce the morbidity and mortality of NCD.

\section{Additional file}

Additional file 1: List of medicines surveyed.

\footnotetext{
Abbreviations

$\mu \mathrm{g}$ : Microgram; COPD: Chronic obstructive pulmonary diseases; DDD: Defined Daily Dose; DPI: Dry Powder Inhaler; EM: Essential Medicines; EML: Essential Medicine List; ERC: Ethical Review Committee; HAl: Health Action International; IRP: International Reference Price; IU: International units; LPG: Lowest Price Generics; MDGs: The UN's Millennium Development Goals; MDI: Metered Dose Inhaler; mg: Milligram; ml: Millilitre; MPR: Median Price Ratio; MSD: Medical Supplies Division; NCD: Non communicable diseases; OB: Originator Brand; OPD: Outpatient Department; SD: Standard deviation; SEAR: South East Asian Region; SL-EML: Sri Lanka-Essential Medicines List;
}

SLR: Sri Lankan rupees; SPC: State Pharmaceuticals Corporation; USD: US dollar; WHO: World Health Organization.

\section{Competing interests}

The authors declare that they have no competing interests.

\section{Authors' contributions}

All authors contributed to the paper's conception and design, analysis and interpretation of the data, drafting of the article, and critical revision. All authors have seen and approved the final version.

\section{Authors' information}

PRL = Probationary Lecturer, Department of Allied Health Sciences, Faculty of Medical Sciences, University of Sri Jayewardenepura, Sri Lanka.

CAW = Senior Lecturer, Department of Pharmacology, Faculty of Medical Sciences, University of Sri Jayewardenepura, Sri Lanka.

BVSH = Director, Directorate of Medical Technology and Supplies, Ministry of Healthcare and Nutrition, Sri Lanka.

\section{Acknowledgements}

We thank the WHO country office Sri Lanka for financial assistance and the Ministry of Health, Sri Lanka and the State Pharmaceuticals Cooperation for the administrative support given to conduct this study. The cooperation extended by the private pharmacies is also acknowledged.

\section{Author details}

'Department of Allied Health Sciences, Faculty of Medical Sciences, University of Sri Jayewardenepura, Nugegoda, Sri Lanka. ${ }^{2}$ Department of Pharmacology, Faculty of Medical Sciences, University of Sri Jayewardenepura, Nugegoda, Sri Lanka. ${ }^{3}$ Directorate of Medical Technology and Supplies, Ministry of Healthcare and Nutrition, Colombo, Sri Lanka.

Received: 4 May 2014 Accepted: 4 August 2014

Published: 8 August 2014

\section{References}

1. United Nations Publication: Indicators for Monitoring the Millennium Development Goals. United Nations Development Group; 2003.

2. World Health Organization: WHO medicines strategy. Geneva, Switzerland: Countries at the core 2004-2007; 2004.

3. Ministry of Health: National list of Essential medicines Sri Lanka: 5th Revision, 2013-2014. Sri Lanka; 2013.

4. WHO/HAl: Measuring medicine prices, availability, affordability and price components. 2nd edition. Geneva, Switzerland; 2008.

5. World Health Organization: Preventing chronic disease: a vital investment. Geneva, Switzerland; 2005.

6. World Health Organization: Prevention of recurrent heart attacks and strokes in low and middle income populations: evidence-based recommendations for policy-makers and health professionals. Geneva, Switzerland; 2003.

7. Hogerzeil HV, Jonathan L, Wirtz VJ, P Kishore SP, Selvaraj S, Kiddell-Monroe R, Mwangi-Powell FN FN, von Schoen-Angerer T: Promotion of access to essential medicines for non-communicable diseases: practical implications of the UN political declaration. Lancet 2013, 381:680-689.

8. Mendis S, Fukino K, Cameron A, Laing R, Filipe A Jr, Khatib O, Leowski J, Ewene M: The availability and affordability of selected essential medicines for chronic diseases in six low- and middle-income countries. Bull World Health Org 2007, 85(4):279-287.

9. Yusuf S, Islam S, Chow CK, Rangarajan S, Dagenais G, Diaz R, Gupta R, Kelishadi R, lqbal R, Avezum A, Kruger A, Kutty R, Lanas F, Lisheng L, Wei L, Lopez-Jaramillo P, Oguz A, Rahman O, Swidan H, Yusoff K, Zatonski W, Rosengren A, Teo KK: Use of secondary prevention drugs for cardiovascular disease in the community in high-income, middle-income, and low-income countries (the PURE Study): a prospective epidemiological survey. Lancet 2011, 378:1231-1243.

10. Ministry of Finance \& Planning: Annual bulletin of medical statistics. Sri Lanka; 2009. http://203.94.76.60/health/eng/publications/AHB/News\%20Letter\% 20Format\%20\%28English\%29.pdf

11. Ministry of Healthcare and Nutrition: Sri Lanka - health at a glance. Vol 1 Sri Lanka; 2008.

12. Non communicable diseases in the South-East Asia Region: Situation and response 2011. In Regional Office for South-East Asia: World Health 
Organization. http://203.94.76.60/health/eng/publications/AHB/News\%20Letter \%20Format\%20\%28English\%29.pdf.

13. Indralal De Silva W: The Age Structure Transition and the Demographic Dividend: An Opportunity for Rapid Economic Take-off in Sri Lanka. Sri Lanka J Adv Soc Stud 2012, 2(1):3-46.

14. Fernando WHKN, Wijesinghe DGNG: Assessment of Nutritional Status and Disease Prevalence among Elderly Population in Elderly Homes in Kandy. Tropical Agric Res 2010, 21(3):229-237.

15. Sri Lanka Census of Population and Housing. In 2012. http://www. statistics.gov.lk/PopHouSat/CPH2011/Pages/Activities/Reports/ CPH_2012_5Per_Rpt.pdf.

16. Ganga Senarathna SMDK: Uthpali Mannapperuma, B 381.M. Rohini Fernandopulle.: Medicine prices, availability and affordability in Sri Lanka. Indian J Pharmacol 2011, 43(1):60-63.

17. Balasubramaniam R, Beneragama BVSH, Sri Ranganathan S: A national survey of availability of key essential medicines for children in Sri Lanka. Ceylon Med J 2011, 56(3):101-107. 386

18. Ministry of Healthcare and Nutrition: National list of Essential medicines Sri Lanka, 4th Revision. Sri Lanka; 2009.

19. Gelders S, Ewen M, Noguchi N, Laing R: Price, availability and affordability: An International comparison of chronic diseases medicines. World Health Organization and Health Action International: Cairo; 2006

20. Frye JE (Ed): International drug price indicator guide. USA: Management Sciences for Health; 2012

21. The Gazette of the Democratic Socialist Republic of Sri Lanka, extraordinary. In 2012 [http://www.pubad.gov.lk/web/images/stories/dos/ $\mathrm{sm} / \mathrm{sm} \% 28 \mathrm{e} \% 29$.pdf]

22. van Mourik M, Alexandra C, Marg E, Laing RO: Availability, price and affordability of cardiovascular medicines: A comparison across 36 countries using WHO/HAl data. BMC Cardiovasc Disord 2010, 10:25.

23. WHO: The Selection of essential drugs. Report of the WHO Expert Committee. 2011 (including the 17th model list of Essential Medicines and 3rd WHO model list of Essential Medicines for Children) Technical Report Series No. 965. Geneva: WHO; 2011

24. Perera BJC, Cooray JHL (Eds): Sri Lanka Medical Association: Guidelines on the Management of Asthma. 3rd edition. Sri Lanka; 2005.

doi:10.1186/1471-2458-14-817

Cite this article as: Dabare et al:: A national survey on availability, price and affordability of selected essential medicines for non communicable diseases in Sri Lanka. BMC Public Health 2014 14:817.

\section{Submit your next manuscript to BioMed Central and take full advantage of:}

- Convenient online submission

- Thorough peer review

- No space constraints or color figure charges

- Immediate publication on acceptance

- Inclusion in PubMed, CAS, Scopus and Google Scholar

- Research which is freely available for redistribution 